\title{
Loss to Follow-Up among HIV Positive Pregnant and Lactating Mothers on Lifelong Antiretroviral Therapy for PMTCT in Rural Uganda
}

\author{
Matilda Kweyamba (D), ${ }^{1,2}$ Esther Buregyeya, ${ }^{2}$ Joy Kusiima, ${ }^{3}$ \\ Vianney Kweyamba $\mathbb{D}^{4},{ }^{4}$ and Aggrey David Mukose ${ }^{2}$ \\ ${ }^{1}$ Cornerstone Surgery, Kampala, Uganda \\ ${ }^{2}$ School of Public Health, Makerere University College of Health Sciences, Kampala, Uganda \\ ${ }^{3}$ FETP Fellowship Program, Uganda Cancer Institute, Kampala, Uganda \\ ${ }^{4}$ Department of Surgery, Naguru Regional Referral Hospital, Kampala, Uganda \\ Correspondence should be addressed to Matilda Kweyamba; mkweyamba@yahoo.com
}

Received 27 December 2017; Revised 7 May 2018; Accepted 31 May 2018; Published 2 July 2018

Academic Editor: Julio Diaz

Copyright ( 2018 Matilda Kweyamba et al. This is an open access article distributed under the Creative Commons Attribution License, which permits unrestricted use, distribution, and reproduction in any medium, provided the original work is properly cited.

\begin{abstract}
Background. Mother-to-Child Transmission of HIV accounts for more than $90 \%$ of all pediatric HIV infections. However, Prevention of Mother-to-Child Transmission (PMTCT) of HIV through provision of lifelong ART to HIV positive mothers faces various challenges which affect its success. One of such challenges is the loss to follow-up (LTFU) of mothers. Methodology. We conducted a cross-sectional study utilizing both quantitative and qualitative data collection methods. We were able to trace 279 HIV positive, pregnant, and lactating mothers among mothers who were initiated on lifelong ART for PMTCT in public health facilities in Ntungamo district, Western Uganda. The proportion of those who were lost to follow-up was determined, and Log binomial regression with stepwise backward elimination method was employed to identify factors associated with LTFU. Focus group discussions (FDGs) of women on lifelong ART and key informant interviews (KIIs) of peer educators were also performed. Results. Out of the 279 mothers that were successfully traced and interviewed, 103 (37\%) were identified as lost to follow-up. The prevalence of LTFU was higher among those whose transport costs were above \$2.75, adj (adjusted) PR (Prevalence Ratio) 1.6 (95\% CI; 1.02-2.55); those who waited beyond one hour before being attended to, adj PR 1.74 (95\% CI; 1.02-2.96); and those who assumed that their infant was already infected, adj PR 1.76 (95\% CI; 1.15-2.70). On interviews, LTFU in these mothers was attributed to fear of swallowing antiretroviral drugs, HIV related stigma and discrimination, inadequate facilitation of the peer educators, long patient waiting time, and transportation to the health facilities. Conclusion. More than one-third of mothers initiated on lifelong ART for PMTCT in Ntungamo district were lost to follow-up over a period of 25 months. Recommendations. Provision of regular and adequate pre-ART and ART adherence counseling and provision of routine health education would reduce LTFU.
\end{abstract}

\section{Background}

Mother-to-Child Transmission (MTCT) of HIV accounts for more than $90 \%$ of all new pediatric HIV infections [1]. It may occur in utero, during labor, during delivery, and/or during breastfeeding [1]. Without any intervention, the MTCT rate of HIV transmission would range from $25 \%$ to $45 \%$ [1]. The use of combined antiretroviral therapy (ART) and elective caesarean section has reduced MTCT rates to less than $2 \%$ in non-breastfeeding populations. Among breastfeeding populations, studies have demonstrated that timely antiretroviral therapy (ART) can reduce MTCT of HIV to $5 \%$ or less [2-4]. In view of these studies and more in 2010, UNAIDS set a target for member states to have virtual elimination of MTCT, defined as reducing MTCT to less than $5 \%$ and $90 \%$ reduction of new HIV infections among young children by 2015 [5]. However, poor uptake of Prevention of Mother-to-Child Transmission (PMTCT) of HIV services, Loss to Follow-Up (LTFU), and poor adherence to drugs are still a major challenge to achieving virtual elimination of 
MTCT of HIV especially in Sub-Saharan Africa [6]. Reducing LTFU among mothers initiated on lifelong ART for PMTCT is therefore a crucial step towards elimination of MTCT of HIV.

In a 2014 Malawian study, $23.5 \%$ of the mothers who were initiated on lifelong ART at the antenatal clinic were lost to follow-up after one year [7]. Lifelong ART for PMTCT entails the use of HAART for all HIV positive pregnant and lactating mothers for life. The guidance on PMTCT is provided to countries by World Health Organization (WHO) and Ministry of Health of Uganda adapted these guidelines to eliminate MTCT of HIV in the country [8].

In 2002, Uganda adopted and began implementing the first National PMTCT guidelines. This came as recommendations from findings of the PMTCT pilot program of 2000 which had over time expanded to cover 56 districts by the end of 2003 [9]. The main drug that was being used for HIV positive mothers during labor was Nevirapine single dose tablet (SdNvp). In 2006, WHO recommended use of zidovudine (AZT) during pregnancy combined with SdNvp at delivery to the mother at onset of labor and to the newborn, then followed by two weeks of zidovudine and lamivudine (AZT/3TC) to the mother to reduce the risk of emergency resistant virus. Uganda as a country adopted these PMTCT guidelines and this treatment option was called Option A.

In 2010, Uganda adopted a third set of World Health Organization (WHO) guidelines. The recommendations were either use of Option A (maternal AZT during pregnancy plus SdNvp at delivery to the mother and the newborn and two weeks of AZT/3TC to the mother) or the use of highly active antiretroviral therapy (HAART) also known as Option $B$ regimen [8]. In 2012, Uganda transitioned to the new (4th) set of WHO PMTCT guidelines with the implementation of Option B+ (lifelong ART). By 2013-2014, the rapid roll-out had covered all districts in the country.

According to the Ministry of Health of Uganda, these new policy guidelines focus not only on eliminating HIV transmission via mother to child, but also on reducing mortality and morbidity among HIV positive women and their HIV exposed or infected infants [8].

In Ntungamo district, the program was launched in March 2013 with the support of Elizabeth Glaser Pediatric AIDs foundation (EGPAF). EGPAF is a non-governmental organization (NGO) running HIV and TB services in the southwestern part of Uganda. Health facilities in Ntungamo district that were implementing the 2nd PMTCT guidelines (Option A) slowly transitioned to lifelong ART (the 4th PMTCT guidelines). EGPAF built capacity for health workers to provide lifelong ART services in high patient volume sites (health centre (HC) IVs and hospitals) and later scaled up to lower volume sites (HCIIIs). This was followed up with mentorships and provision of necessary logistics to enable a smooth transition.

However, several challenges have been noted in the implementation of the lifelong ART program and such challenges include mothers initiated on HAART either during pregnancy, delivery, or breastfeeding getting lost along the way and not returning to the clinic for monitoring [8]. Monitoring adherence and retention for mothers on Option
$\mathrm{B}+$ are still a big challenge and yet information has already shown that there is substantial LTFU [8].

We aimed at determining the proportion of those on lifelong ART for PMTCT in Ntungamo district who were lost to follow-up and associated factors.

\section{Methods}

2.1. Study Design. This was a cross-sectional study which employed both qualitative and quantitative methods of data collection.

2.2. Study Setting. The study was carried out in Ntungamo district, located in south western Uganda. The district has 42 health facilities of which one hospital and 16 health centres offer PMTCT. However, eight of these health facilities had adopted and were offering lifelong ART for PMTCT in the district, between September 1st, 2013, and September 30th, 2015. The study involved mothers who were attended to at these health facilities during this period. It also included peer mothers that were once enrolled on lifelong ART and were involved in the follow-up of mothers on PMTCT within the district.

\subsection{Selection Criteria}

Inclusion Criteria. All mothers who were identified as having been enrolled on lifelong ART for PMTCT from 1st September 2013 to 30th September 2015, as documented in the PMTCT and ART registers, were included.

\section{Exclusion Criteria}

(i) Mothers who had no telephone contact and/or no clear physical address.

(ii) Mothers who could not be traced to their physical address. That is, those who had either changed physical address or changed the telephone contact.

\subsection{Sample Size Determination}

Quantitative Component. All mothers that had a telephone contact or clear physical address were traced. Those successfully traced were included in the study.

Qualitative Study. Two focus group discussions (FGDs) with mothers initiated on lifelong ART and attending family support groups (FSGs) and fifteen key informant interviews (KIIs) with peer educators were conducted.

\subsection{Sampling Procedure}

Sampling for Quantitative Study. Names and contacts of mothers that were initiated on lifelong ART for PMTCT between 1st September 2013 and 30th September 2015 (period of study) were obtained from the ANC/PMTCT and ART clinic registers of the 8 health facilities that were offering lifelong ART for PMTCT at that time. These formed the sampling frame for the study. All mothers that had been 
enrolled on lifelong ART for PMTCT from 1st September 2013 to 30th September 2015 were considered. However, mothers that either did not have a clear contact address or had no telephone contact recorded in the individual ART card were disregarded. The selected respondents were physically identified using their telephone contacts and physical address as recorded in their individual ART cards and ANC/PMTCT/ ART clinic registers, with the help of peer educators and or village health teams (VHTs), a method that has also been suggested by Gwadz [10].

Sample Selection for Qualitative Study. The respondents for qualitative data included peer educators and HIV positive pregnant and lactating mothers under care on lifelong ART. This was carried out in the five peer supported health facilities. These are facilities that have high volume with many HIV patients attending the HIV clinic. In each of the five facilities, 3 KIIs with peer educators were conducted.

Two focus group discussions were conducted at two facilities that had the highest patient volumes in the district. The FDGs were conducted among pregnant and lactating mothers on lifelong ART for PMTCT during clinic days.

\subsection{Data Collection}

Quantitative Data Collection. Records of mothers in the eight health facilities were extracted from the PMTCT and ART registers using abstraction forms that were developed to capture the names, telephone contacts, next of kin, and physical address. Information relating to the mothers' physical address and telephone contact was extracted from the ART card. Information on sociodemographic characteristics of the mothers was collected through a structured questionnaire that was administered to the mothers. Additional information collected through the structured questionnaire included information on individual and interpersonal factors, peer and family support, health provider attitudes, date of last clinic visit, transportation to health facility, stigma and discrimination, patient waiting time, and health beliefs.

Qualitative Data Collection. Qualitative data was collected through FGDs with mothers and KIIs with peer educators. These were conducted with the help of a focus group and key informant interview guides. The FGDs, consisting of 25-30 members each, explored perception towards PMTCT program, challenges in accessibility of PMTCT services, challenges faced because of being HIV positive, support of family members, reasons why mothers get LTFU, and proposed interventions to reduce LTFU of mothers.

Fifteen KIIs were held with peer educators who work with health workers and are assigned the duty of follow-up of mothers once enrolled into PMTCT care. During the FGDs, two research assistants were present: one is to facilitate the discussion while the other was taking notes. Audio recordings for both FGDs and KIIs were also taken by the PI during the interactions, with permission from the respondents.

2.7. Statistical Analysis. We analyzed data using STATA version 12. Percentages were used to determine the proportion of HIV positive pregnant and lactating mothers enrolled on lifelong ART for PMTCT, who were lost to follow-up defined as HIV positive pregnant and lactating mothers initiated on lifelong antiretroviral therapy (ART) for PMTCT that had not returned to the clinic in $>90$ days from their last scheduled appointment.

Log binomial regression was used to determine factors associated with LTFU among pregnant and lactating mothers initiated on lifelong ART. Prevalence ratios were used as the measure of association since the outcome (LTFU) was $>10 \%$ (37\%).

Following bivariable analysis, we selected variables with a significance level of $10 \%(\mathrm{P}<0.1)$ for inclusion in the multivariable analysis. Multivariable analysis was done using the stepwise approach-backward elimination method. Statistical significance of variables for inclusion in the final model was set at a $\mathrm{p}$ value $<0.05$.

2.8. Ethics Considerations. This study was approved by Makerere University School of Public Health Higher Degrees Research and Ethics Committee and permission was obtained from the District Health Officer in Ntungamo. All respondents eligible for the study provided written consent. To ensure confidentiality, all interviews were conducted in privacy and respondent questionnaires were identified using unique identifiers.

\section{Results}

Overall 480 mothers were identified as having been initiated on lifelong ART for PMTCT between September 1st, 2013, and September 30th, 2015; of these 302 mothers met the inclusion criteria (had a clear physical address or a telephone contact). However, 279 mothers were successfully traced and these were included in the study. Out of these 279 mothers, $103(37 \%)$ were identified as lost to follow-up.

\subsection{Quantitative Findings}

3.1.1. Demographics Characteristics of the Mothers and Their Individual Perceptions. The mean age (SD) was 28.2 (4.6) years and the median age (IQR) was 28 (25-30 years) and 106 $(38 \%)$ of the mothers were in the age range of 24 to 28 years. $74 \%$ were married and $56 \%$ were subsistence farmers. Over 99\% knew that the drug was safe for them and the baby and that the administered drug works. Majority of the mothers had positive perceptions towards the medication they were receiving; however, approximately one-third (29.3\%) feared taking their medication, and a quarter reported having experienced side effects (25.9\%) (Table 1).

3.1.2. Proportion of Mothers LTFU. We successfully traced and interviewed 279 HIV positive pregnant and lactating mothers. Of the 279 mothers interviewed, 103 (37\%) were lost to follow-up (Figure 1)

3.1.3. Factors Associated with LTFU. From the bivariate analysis, variables that had a $\mathrm{p}$ value of $<0.1$, such as fear of 
TABLE 1: Social demographic characteristics of the mothers $(\mathrm{N}=279)$ and individual perceptions of HIV positive women towards highly active antiretroviral therapy (HAART).

\begin{tabular}{|c|c|c|}
\hline Demographic characteristics & Frequency (n) & Percent (\%) \\
\hline \multicolumn{3}{|l|}{ Age } \\
\hline Mean (sd) & $28.2(4.6)$ & \\
\hline Median $(I Q R)$ & $28(25-30)$ & \\
\hline \multicolumn{3}{|l|}{ Age_resp } \\
\hline $19-23$ & 46 & 16.5 \\
\hline $24-28 y r s$ & 106 & 38 \\
\hline 29-33 yrs & 92 & 33 \\
\hline $34-38 y r s$ & 30 & 11 \\
\hline$>38$ yrs & 5 & 1.8 \\
\hline \multicolumn{3}{|l|}{ Religion } \\
\hline Catholic & 79 & 27.9 \\
\hline Muslim & 22 & 7.9 \\
\hline Evangelical & 34 & 12.2 \\
\hline Anglican/Presbyterian & 144 & 51.6 \\
\hline \multicolumn{3}{|l|}{ Tribe } \\
\hline Acholi & 3 & 1.1 \\
\hline Muganda & 15 & 5.4 \\
\hline Mukiga & 40 & 14.4 \\
\hline Munyankole & 202 & 72.7 \\
\hline Munyarwanda & 15 & 5.4 \\
\hline Other & 4 & 1 \\
\hline \multicolumn{3}{|l|}{ Marital status } \\
\hline Divorced & 36 & 12.9 \\
\hline Married & 207 & 74.2 \\
\hline single & 18 & 6.5 \\
\hline Widowed & 18 & 6.5 \\
\hline \multicolumn{3}{|l|}{ Occupation } \\
\hline Subsistence farmer & 156 & 56.5 \\
\hline House wife & 43 & 15.6 \\
\hline Causal laborer & 24 & 8.7 \\
\hline Professional & 28 & 10.1 \\
\hline Business woman & 25 & 9.1 \\
\hline \multicolumn{3}{|l|}{ Individual perceptions } \\
\hline \multicolumn{3}{|c|}{ Perceive administered drug is safe for me and baby } \\
\hline No & 3 & 1.1 \\
\hline Yes & 276 & 98.9 \\
\hline \multicolumn{3}{|c|}{ Perceive that administered drug works } \\
\hline No & 6 & 2.2 \\
\hline Yes & 272 & 97.8 \\
\hline \multicolumn{3}{|l|}{ Fear swallowing ARVs } \\
\hline No & 198 & 71 \\
\hline Yes & 81 & 29 \\
\hline \multicolumn{3}{|c|}{ Ever experienced side effects when swallowing ARVs } \\
\hline No & 206 & 74.1 \\
\hline Yes & 72 & 25.9 \\
\hline \multicolumn{3}{|l|}{ Perceived ease of receiving $A R V s$} \\
\hline No & 5 & 1.8 \\
\hline Yes & 274 & 98.2 \\
\hline
\end{tabular}


TABLE 1: Continued.

\begin{tabular}{lcc}
\hline Are ARVs offered free & 3 & \\
No & 276 & \\
Yes & & \\
Do you think you can infect your child with HIV & 117 & \\
No & 158 & \\
Yes & & 52.1 \\
Do you think you need ARVS & 5 & \\
No & 57.5 \\
Yes & 274 & 98.2 \\
\hline
\end{tabular}

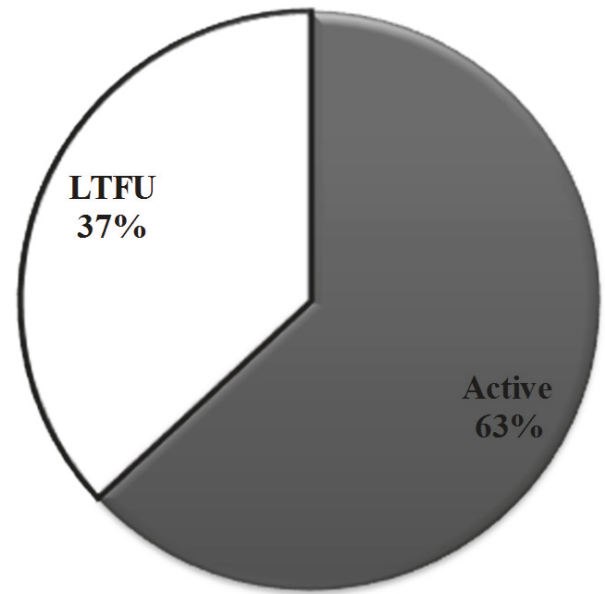

FIgure 1: Proportion of mothers on lifelong ART for PMTCT who were lost to follow-up between Sept 2013 and Sept 2015, n= 279 .

swallowing ARV drugs, perception that the mother can infect the child, disclosure to other relatives other than the spouse, and transport costs, were analyzed further in multivariable analysis.

At multivariable analysis, transport costs above $\$ 2.75$ (adj PR 1.6, CI: 1.02-2.55), waiting time greater than 1 hour (adj PR 1.74, CI: 1.02-2.96), and perception that the child is already infected (adj PR 1.76, CI: 1.15-2.70) were the factors significantly associated with loss to follow-up, $\mathrm{p}$ value $<0.05$. However, the mother knowing that ARV drugs work (adj PR 0.35, CI: 0.23-0.56) was protective (Table 2).

3.2. Qualitative Findings. Qualitative evaluation was done to explore further mothers views as to why women on lifelong ART get lost to follow-up. A total of two focus group discussions (FGDs) with mothers and 15 key informant interviews (KIIs) with peer mothers were conducted. The factors that were repeatedly common throughout these interviews were fear of swallowing ARV drugs, domestic violence following disclosure, HIV related stigma and discrimination, inadequate facilitation of peer educators and mothers, long patient waiting time, and cost of transportation to the health facilities.

\section{Discussion}

This study found that the proportion of mothers who get lost to follow-up from the PMTCT program was 37\%. A study done in Malawi revealed the LTFU as 30\% after 3 years of initiation on lifelong ART [11]. This is an indication that there is significant LTFU of mothers initiated on lifelong ART for PMTCT. Therefore, addressing the associated factors will go a long way to reduce this loss, hence leading to the sustainable achievement of elimination of MTCT.

Mothers who had to incur transport costs above $\$ 2.75$ (adj PR 1.6, CI: 1.02-2.55) were more likely to be lost to follow-up. In a rural setting transport is costly because most mothers are subsistence farmers with a poor socioeconomic status. This forces mothers to resort to walking long distances. This finding is in agreement with other studies, where distance to the clinic and transport cost were found to be major barriers to retention in care in a wide variety of settings in Africa including Uganda [12].

Waiting at the health facility for more than an hour before being attended to by a health worker was a predictor of LTFU (adj PR 1.74, CI: 1.02-2.96). This may be a result of low staffing levels compared to the large volumes of patients, hence leading to the long waiting time. A study done in Northern Uganda also noted that high patient loads at the facilities caused long patient waiting times [13]. Preventing batching up, that is, having all patients flooding the clinic at the same time very early in the morning, synchronizing staff shifts so as to have more staff on duty during clinic days, triaging of the mothers in order to separate critically ill from those walking or for refill, and provision of health education may go far in reducing the waiting times or make them endurable [14].

Knowing that the mother could infect their baby was a predictor for LTFU (adj PR 1.76, CI: 1.15-2.70). This indicates that mothers are knowledgeable about the transmission of HIV to their babies. But, upon defaulting from the PMTCT, they perceive that their breastfed child is HIV positive and hence fear returning to the clinic to avoid being blamed by the health workers if the child turns out to be HIV positive on testing. Improving health provider attitudes and providing customer care training to health providers could help change the way patients perceive care and their choice on whether to continue receiving care or not.

Interviews from the qualitative evaluation also noted high transport costs and long patient waiting time as some of the predictors of loss to follow-up. Other factors that were 
TABLE 2: Factors associated with LTFU among HIV positive pregnant and lactating mothers on lifelong ART for PMTCT.

\begin{tabular}{|c|c|c|c|c|}
\hline & $\begin{array}{l}\text { Proportion lost to } \\
\text { follow-up }\end{array}$ & $\begin{array}{l}\text { Crude PR } \\
(95 \% \text { CI })\end{array}$ & $\begin{array}{c}\text { Adjusted PR } \\
(95 \% \text { CI })\end{array}$ & P value \\
\hline \multicolumn{5}{|l|}{ Age (years) } \\
\hline $19-23$ & $16 / 46$ & Ref & & \\
\hline $24-28 y r s$ & $39 / 106$ & $1.05(0.66-1.7)$ & & \\
\hline 29-33 yrs & $31 / 92$ & $0.96(0.59-1.58)$ & & \\
\hline $34-38$ yrs & $16 / 30$ & $1.53(0.91-2.57)$ & & \\
\hline$>39 y r s$ & $1 / 5$ & $0.46(0.48-4.55)$ & & \\
\hline \multicolumn{5}{|l|}{ Religion } \\
\hline Catholic & $32 / 79$ & Ref & & \\
\hline Muslim & $7 / 22$ & $1.4(0.92-2.06)$ & & \\
\hline Evangelical & $19 / 34$ & $0.78(0.4-1.53)$ & & \\
\hline Anglican/Presbyterian & $45 / 144$ & $0.77(0.53-1.1)$ & & \\
\hline \multicolumn{5}{|l|}{ Marital status } \\
\hline single & $8 / 18$ & Ref & & \\
\hline Married & $76 / 207$ & $0.83(0.47-1.43)$ & & \\
\hline Divorced & $15 / 36$ & $0.94(0.49-1.79)$ & & \\
\hline Widowed & $4 / 18$ & $0.5(0.08-1.52)$ & & \\
\hline \multicolumn{5}{|l|}{ Occupation } \\
\hline Subsistence farmer & $62 / 156$ & Ref & & \\
\hline Home maker & $17 / 43$ & $0.99(0.65-1.5)$ & & \\
\hline Causal laborer & $9 / 24$ & $0.94(0.54-1.6)$ & & \\
\hline Professional & $7 / 28$ & $0.63(0.32-1.23)$ & & \\
\hline Self employed & $6 / 25$ & $0.6(0.29-1.24)$ & & \\
\hline \multicolumn{5}{|l|}{ Tribe } \\
\hline Muganda & $7 / 15$ & Ref & & \\
\hline Munyankole & $75 / 202$ & $0.79(0.45-1.41)$ & & \\
\hline Mukiga & $16 / 40$ & $0.86(0.44-1.66)$ & & \\
\hline Acholi & $0 / 3$ & Omitted & & \\
\hline Munyarwanda & $3 / 15$ & $0.43(0.14-1.35)$ & & \\
\hline Other & $1 / 3$ & $0.7(0.31-3.8)$ & & \\
\hline \multicolumn{5}{|c|}{ Perceptions towards HAART } \\
\hline \multicolumn{5}{|c|}{ Perceive admin drug is safe for me and baby } \\
\hline No & $1 / 3$ & Ref & & \\
\hline Yes & $102 / 276$ & $1.17(0.2-5.5)$ & & \\
\hline \multicolumn{5}{|c|}{ Perception that administered drug works } \\
\hline No & $6 / 6$ & Ref & & \\
\hline Yes & $97 / 272$ & $0.35(0.30-0.42)$ & $0.35(0.23-0.56)$ & 0.00 \\
\hline \multicolumn{5}{|l|}{ Fear to swallow ARVs } \\
\hline No & $62 / 198$ & Ref & & \\
\hline Yes & $41 / 81$ & $1.62(1.19-2.18)$ & $0.77(0.51-1.2)$ & 0.23 \\
\hline \multicolumn{5}{|c|}{ Ever experienced side effects after swallowing $A R V s$} \\
\hline No & $76 / 206$ & Ref & & \\
\hline Yes & $27 / 72$ & $1.02(0.72-1.44)$ & $0.84(0.45-1.57)$ & 0.59 \\
\hline \multicolumn{5}{|c|}{ Perceived ease of receiving ARVs } \\
\hline No & $3 / 5$ & Ref & & \\
\hline Yes & $100 / 274$ & $0.6(0.29-1.26)$ & & \\
\hline
\end{tabular}


TABLE 2: Continued.

\begin{tabular}{|c|c|c|c|c|}
\hline & $\begin{array}{l}\text { Proportion lost to } \\
\text { follow-up }\end{array}$ & $\begin{array}{l}\text { Crude PR } \\
(95 \% C I)\end{array}$ & $\begin{array}{c}\text { Adjusted PR } \\
(95 \% \mathrm{CI})\end{array}$ & $P$ value \\
\hline \multicolumn{5}{|l|}{ Is the drug easy to swallow } \\
\hline No & $7 / 18$ & Ref & & \\
\hline Yes & $96 / 261$ & $0.91(0.34-2.43)$ & & \\
\hline \multicolumn{5}{|l|}{ Are ARVs offered free } \\
\hline No & $1 / 3$ & Ref & & \\
\hline Yes & $102 / 276$ & $1.1(0.2-5.5)$ & & \\
\hline \multicolumn{5}{|c|}{ Do you think you can infect your child with $H I V^{* *}$} \\
\hline No & $33 / 117$ & Ref & & \\
\hline Yes & $66 / 158$ & $1.5(1.05-2.1)$ & $1.72(1.13-0.62)$ & 0.01 \\
\hline \multicolumn{5}{|l|}{ Do you think you need ARVS } \\
\hline No & $2 / 5$ & Ref & & \\
\hline Yes & $101 / 274$ & $0.92(0.31-2.7)$ & & \\
\hline \multicolumn{5}{|l|}{ Mode of transport to facility } \\
\hline Walking & $29 / 71(40.8)$ & Ref & & \\
\hline Taxi & $40 / 99(40.4)$ & $0.98(0.68-1.43)$ & & \\
\hline Boda boda (motor cycle) & $72 / 106(32.0)$ & $0.78(0.53-1.16$ & & \\
\hline \multicolumn{5}{|l|}{ Total Transport Cost ${ }^{* *}$} \\
\hline$<5000$ shs & $30 / 99(30.3 \%)$ & Ref & & \\
\hline $5001-10000 \mathrm{shs}$ & $25 / 73(34.2 \%)$ & $1.13(0.7-1.74)$ & $1.09(0.70-1.7)$ & 0.7 \\
\hline$>10001$ & $18 / 34(52.1 \%)$ & $\begin{array}{l}1.75(1.12- \\
2.74)^{* *}\end{array}$ & $1.57(1.002-2.4)$ & 0.049 \\
\hline \multicolumn{5}{|c|}{ Waiting time between arriving and receiving service } \\
\hline$<30 \mathrm{~min}$ & $19 / 67(28.3 \%)$ & Ref & & \\
\hline $30 \min -1 \mathrm{hr}$ & $28 / 79(35.4 \%)$ & $1.2(0.77-2.03)$ & $1.5(0.83-2.7)$ & 0.2 \\
\hline$>1 \mathrm{hr}$ & $56 / 133(42.1 \%)$ & $1.5(0.96-2.28)$ & $1.74(1.02-2.96)$ & 0.04 \\
\hline \multicolumn{5}{|l|}{ STIGMA } \\
\hline \multicolumn{5}{|l|}{ Disclosed to spouse } \\
\hline No & $19 / 69$ & Ref & & \\
\hline Yes & $81 / 199$ & $1.48(0.97-2.28)$ & & \\
\hline \multicolumn{5}{|l|}{ Does he support you?** } \\
\hline No & $32 / 68$ & Ref & & \\
\hline Yes & $50 / 135$ & $0.79(0.56-1.10)$ & & \\
\hline \multicolumn{5}{|c|}{ Disclosed to relatives other than spouse } \\
\hline No & 153 & Ref & & \\
\hline Yes & 126 & $1.5(1.10-2.04)$ & $1.38(0.86-1.7)$ & 0.4 \\
\hline \multicolumn{5}{|c|}{$\begin{array}{l}\text { Any one refused to offer any service to you because of } \\
\text { your HIV status }\end{array}$} \\
\hline No & $82 / 243$ & Ref & & \\
\hline Yes & $20 / 35$ & $1.69(1.21-2.38)$ & $1.3(0.84-2.1)$ & 0.2 \\
\hline
\end{tabular}

PR: prevalence ratio.

mentioned as predictors of LTFU included fear of swallowing ARV drugs, domestic violence following disclosure of HIV status, stigma and discrimination, and inadequate facilitation of the peer educators.

Fear of swallowing ARVs as a reason for getting lost to follow-up needs to be recognized. The size and smell of the tablets, taking the medication without an assurance of a meal, and the anticipated side effects are some of the reasons mothers stopped taking the ARVs, hence selfcensoring themselves from coming to the clinic. Studies have also shown that poor adherence to drugs is attributed to the feared side effects [15] and food insecurity [16, 17]. Health Education coupled with initial and ongoing HIV and adherence counseling especially with the help of peers will help dispel the myths that are associated with the taking of medication. 
Mothers interviewed in this study expressed the fear of stigma and discrimination from the community and family members. This was attributed to the fear of domestic violence after disclosing their status to their spouses. Some quantitative studies have shown this to be true [18].

4.1. Limitation of the Study. The strength of this study is that women were traced to their physical addresses and therefore, we were able to know if a mother was lost to follow-up or active in care. However, this study had some important limitations that should be considered when interpreting the results. First the cross-sectional nature of the study design does not confirm definitive cause and effect relationship between dependent and independent variables. In addition, the study did not account for the mothers that could not be traced and hence could lead to underestimation of the LTFU. In order to get more insight of the study's third objective, we should have conducted in-depth interviews with mothers that we had found to be lost to follow-up as this would give a clear view of why mothers get lost to follow-up. The use of the definition of LTFU in this study as patients who were started on lifelong ART and not seen for more than 90 days after their scheduled appointment has a weakness as some mothers were found to have transferred to other facilities than the original facility where they were initiated on treatment. However, since mothers were being interviewed and had to recall some instances which were used to ascertain LTFU, this could have some recall bias.

4.2. Conclusions. There was substantial LTFU of mothers initiated on lifelong ART for PMTCT in Ntungamo district. Personal fears, wrong perceptions among patients, stigma, discrimination in the community, high transport costs, long patient waiting time, and inadequate facilitation of peer educators are some of the bottlenecks to achieving success desired from the provision of lifelong ART for PMTCT.

4.3. Recommendations. Focus should be directed to provision of regular quality pre-ART and ART adherence counseling, provision of routine health education, strengthening HIV awareness campaigns through local village authorities, increasing HIV outreach services, community engagement, and building community networks through peer support. Large scale research to look at the rates of LTFU at the different points of PMTCT cascade would inform targeted PMTCT interventions.

\section{Abbreviations and Operation Definitions}

Lifelong ART: This is an approach recommended by World Health Organization to prevent mother-to-child HIV transmission with which all HIV positive pregnant and lactating women are initiated on antiretroviral therapy (ART) for life regardless of CD4 count or WHO staging
Loss to follow-up: Patients who were started on lifelong ART and not seen within 90 days of their scheduled appointment

Peer educator: HIV positive patients who are trained to provide peer support and counseling to their fellow HIV positive patients and also follow up mothers by virtue of their good adherence and to some extent their level of education

ANC: Antenatal care

EGPAF: $\quad$ Elizabeth Glaser Pediatric AIDs Foundation

e-MTCT: $\quad$ Virtual Elimination of

HAART: $\quad$ Highly active antiretroviral therapy

HC: $\quad$ Health centre

HIV:

LTFU:

$\mathrm{MCH}$ :

$\mathrm{MOH}$ :

PMTCT: $\quad$ Prevention of Mother-to-Child

Transmission

UNAIDS: $\quad$ United Nations Joint Program

VCT: on AIDS

Voluntary Counseling and Testing

WHO: $\quad$ World Health Organization.

\section{Disclosure}

The corresponding author had full access to all the data in the study and had final responsibility for the decision to prepare the manuscript and submit for publication.

\section{Conflicts of Interest}

The authors declare that there are no conflicts of interest.

\section{Authors' Contributions}

Matilda Kweyamba was responsible for the manuscript from its conception, analysis, and interpretation of data; she drafted the manuscript. Joy Kusiima participated in data analysis and review of the manuscript. Esther Buregyeya participated in the interpretation and review of the manuscript. Aggrey Mukose participated in the interpretation and review of the manuscript. Vianney Kweyamba participated in the drafting, interpretation, and review of the manuscript. All authors approved the final manuscript.

\section{Acknowledgments}

The authors would like to thank the study subjects for their willingness to participate in the study. They would also like to 
thank the district authorities and the various health workers working in the health facilities. Last but not least, heartfelt thanks are due to the research assistants.

\section{References}

[1] "M M. WHO updates HIV treatment guidance for pregnant women and preventing HIV infection in babies: Science Speaks: Global ID News," 2012, http://sciencespeaksblog.org/2012/04/ 09/who-updates-hiv-treatment-guidance-for-pregnant-women -and-preventing-hiv-infection-in-babies/.

[2] C. S. Chasela, M. G. Hudgens, D. J. Jamieson et al., "Maternal or infant antiretroviral drugs to reduce HIV-1 transmission," The New England Journal of Medicine, vol. 362, no. 24, pp. 2271-2281, 2010.

[3] Z. Namukwaya, P. Mudiope, A. Kekitiinwa et al., "The impact of maternal highly active antiretroviral therapy and short-course combination antiretrovirals for prevention of mother-to-child transmission on early infant infection rates at the mulago national referral hospital in Kampala, Uganda, january 2007 to may 2009," Journal of Acquired Immune Deficiency Syndromes, vol. 56, no. 1, pp. 69-75, 2011.

[4] R. L. Shapiro, M. D. Hughes, A. Ogwu et al., "Antiretroviral regimens in pregnancy and breast-feeding in Botswana," The New England Journal of Medicine, vol. 362, no. 24, pp. 22822294, 2010.

[5] Goals MD, Session UNGAS, and Organization WH, PMTCT Strategic Vision 2010-2015: Preventing Mother-to-child Transmission of HIV to Reach the UNGASS and Millennium Development Goals: Moving Towards the Elimination of Paediatric HIV, World health organization (WHO), 2010.

[6] M. Sidibé, Global Report: UNAIDS Report on the Global AIDS Epidemic: 2010, UN Joint Programme on HIV/AIDS (UNAIDS), 2010.

[7] H. Tweya, S. Gugsa, M. Hosseinipour et al., "Understanding factors, outcomes and reasons for loss to follow-up among women in Option B+ PMTCT programme in Lilongwe, Malawi," Tropical Medicine \& International Health, vol. 19, no. 11, pp. 1360-1366, 2014.

[8] "G E. The New National Guidelines (2010) for PMTCT and Infant Feeding in the Context of HIV Kampala: MOH Uganda," 2010, http://library.health.go.ug/publications/service-deliverydiseases-control-prevention-communicable-diseases/hivaids/ new-national.

[9] C. A. S. Karamagi, J. K. Tumwine, T. Tylleskar, and K. Heggenhougen, "Antenatal HIV testing in rural eastern Uganda in 2003: Incomplete rollout of the prevention of mother-to-child transmission of HIV programme?" BMC International Health and Human Rights, vol. 6, 2006.

[10] M. Gwadz, C. M. Cleland, H. Hagan et al., "Strategies to uncover undiagnosed HIV infection among heterosexuals at high risk and link them to HIV care with high retention: A "seek, test, treat, and retain" study," BMC Public Health, vol. 15, no. 1, article no. $481,2015$.

[11] A. D. Haas, L. Tenthani, M. T. Msukwa et al., "Retention in care during the first 3 years of antiretroviral therapy for women in Malawi's option B+ programme: an observational cohort study," The Lancet HIV, vol. 3, no. 4, pp. el75-e182, 2016.

[12] E. H. Geng, D. R. Bangsberg, N. Musinguzi et al., "Understanding reasons for and outcomes of patients lost to follow-up in antiretroviral therapy programs in Africa through a samplingbased approach," Journal of Acquired Immune Deficiency Syndromes, vol. 53, no. 3, pp. 405-411, 2010.

[13] Mugisha A. O. K., S. Edward, L. Ciccio, R. Muwanika, and O. James, "Retention of HIV Positive Persons in Antiretroviral Therapy Programs in Post-Conflict Northern Uganda-Baseline Survey of 17 Health Units," 2009.

[14] M. B. Mavuso, "Patient waiting time at a HIV Clinic in a Regional Hospital in Swaziland," 2008.

[15] M. Ngarina, R. Popenoe, C. Kilewo, G. Biberfeld, and A. M. Ekstrom, "Reasons for poor adherence to antiretroviral therapy postnatally in HIV-1 infected women treated for their own health: experiences from the Mitra Plus study in Tanzania," BMC Public Health, vol. 13, no. 1, article 450, 2013.

[16] W. M. Bezabhe, L. Chalmers, L. R. Bereznicki, and G. M. Peterson, "Adherence to antiretroviral therapy and virologic failure: a meta-analysis," Medicine, vol. 95, no. 15, 2016.

[17] S. D. Weiser, D. M. Tuller, E. A. Frongillo, J. Senkungu, N. Mukiibi, and D. R. Bangsberg, "Food insecurity as a barrier to sustained antiretroviral therapy adherence in Uganda," PLoS ONE, vol. 5, no. 4, Article ID e10340, 2010.

[18] F. W. Kalembo and M. Zgambo, "Loss to Followup: A Major Challenge to Successful Implementation of Prevention of Mother-to-Child Transmission of HIV-1 Programs in SubSaharan Africa," ISRN AIDS, vol. 2012, Article ID 589817, 10 pages, 2012. 


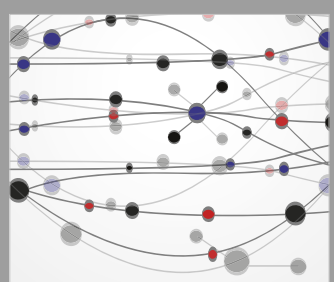

The Scientific World Journal
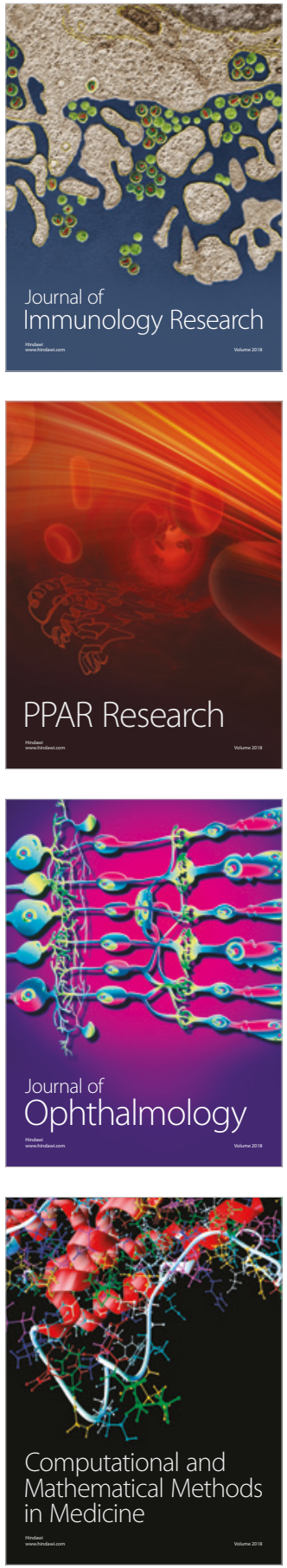

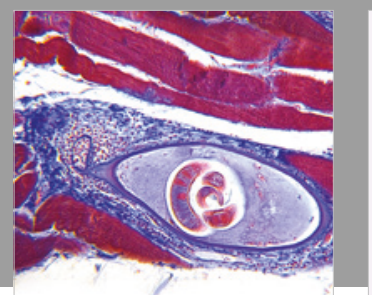

Gastroenterology Research and Practice

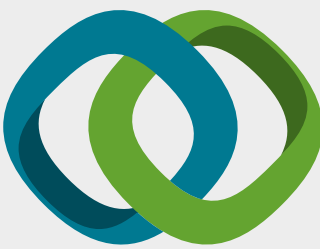

\section{Hindawi}

Submit your manuscripts at

www.hindawi.com
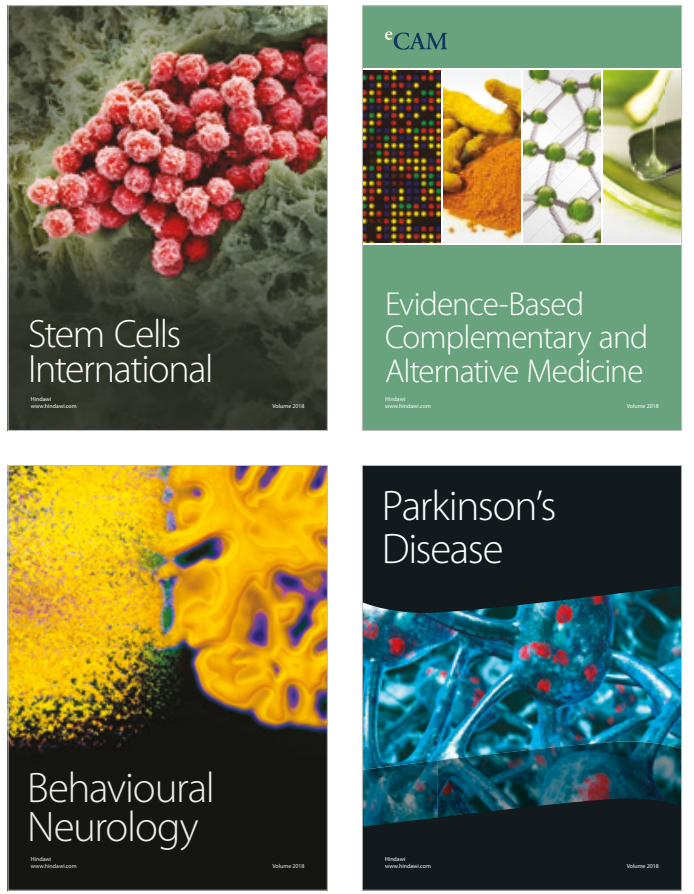

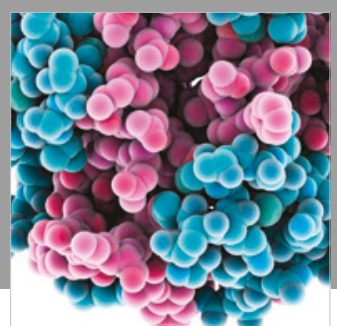

ournal of

Diabetes Research

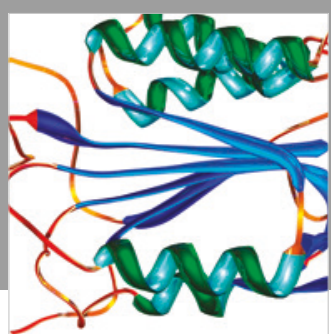

Disease Markers
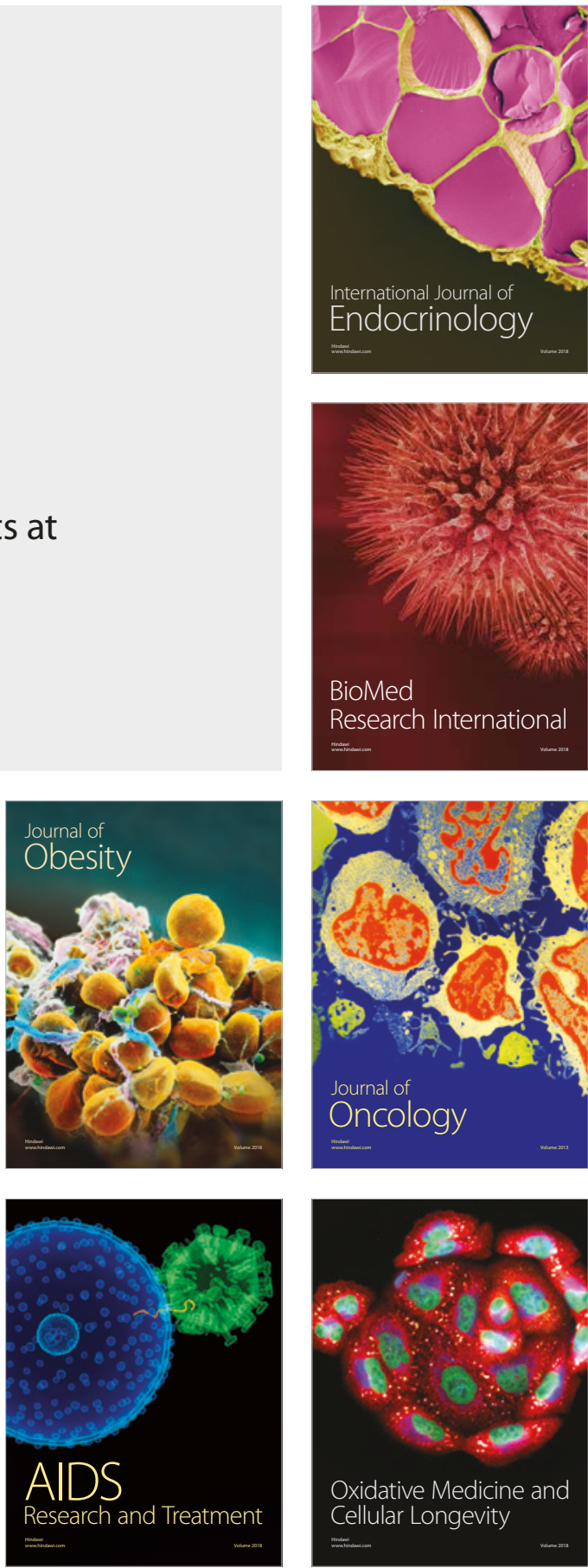